\title{
SOBRE LA NOVELA HISTÓRICA Y SU CLASIFICACIÓN
}

Ana García Herranz anagherranz@hotmail.com

\section{RESUMEN}

El concepto de «novela histórica» engloba casi dos siglos de novelas que se nutren de la historia para su configuración, pero que guardan pocas semejazas formales entre ellas; especialmente se distinguen por su singularidad el episodio nacional y la novela histórica posmoderna hispanoamericana, que deberían formar sendos subgéneros dentro del género de novela histórica.

PALABRAS ClAVE: género literario, subgénero, novela, novela histórica, episodio nacional, novela posmoderna hispanoamericana.

\section{ABSTRACT}

The concept «historical novel» includes almost two centuries of novels that are nourished of the history for her configuration, but that have few formal similarities between them; specially there are distinguished the national episode and the historical postmodern Spanish-American novel, which should be two subgenres inside the historical novel.

KEYWORDS: genre, subgenre, novel, historical novel, national episode, postmodern Spanish-American novel. 


\section{EL CONCEPTO DE NOVELA HISTÓRICA*}

Una clasificación cualquiera de algo implica necesariamente una definición previa de lo clasificado, por tanto, no es de extrañar que la mayor parte de los estudios sobre novela histórica (libros, artículos, tratados o memorias de investigación) que incluyen una o varias clasificaciones de ésta comiencen con una definición de la misma ${ }^{1}$. Esta definición suele presidir y fundamentar la clasificación propuesta.

Así lo podemos comprobar en esta decena de definiciones de novela histórica extraídas de los estudios a los que hacíamos referencia. Estas definiciones suelen basarse - por lo general y de un modo u otro - en un mismo aspecto con el que todas las novelas de este subgénero deben contar para ser considerada como tales: la incorporación de un determinado material histórico en la ficción que esa novela desarrolle. Este material histórico ha de ser considerado convencionalmente y en sentido académico como tal. Pero, también es requisito fundamental, que ese material histórico sea desarrollado por parte del autor con una clara intención de reconstruir o tratar de reconstruir la época en que se sitúa la acción de su novela y, al mismo tiempo, también de presentarla al lector como una época pretérita (Amado Alonso, p. 80). Por tanto, el autor debe imprimir a su novela un marcado sentido histórico y no centrarse exclusivamente en la exactitud de los datos históricos o el amontonamiento de los mismos (Carlos García Gual, 2002, p. 14).

Recrear el pasado con sus peculiaridades implica necesariamente que el autor lo haga desde el conocimiento y la perspectiva que se tenga de esa época en el momento en que escribe su novela, lo que se traduce en un anacronismo inevitable, pero necesario, pues es imprescindible una distancia temporal entre el pasado que se quiere novelar y el momento desde el que se novela. Muy difícil es determinar en años esa distancia temporal, como ya veremos, fuente de verdadera polémica tanto a la hora de definir la novela histórica como a la hora de clasificarla.

Hay, por tanto, en la novela histórica múltiples elementos que la configuran: un material histórico conocido y cronicado, y un autor con la intencionalidad de evocar una época pretérita, que no puede dejar, necesariamente, de practicar el anacronismo. No obstante, dentro de esta ecuación falta incluir dos elementos que dan la verdadera clave de este subgénero literario: el contexto y el lector o público al que va dirigida la novela, pues toda novela histórica (como toda producción literaria) tiene lugar en un determinado momento y para un determinado público. El contexto (tradición cultural y literaria) en el que se sitúan tanto el autor como el lector juega su papel, pues hasta el mismo concepto de lo

\footnotetext{
* Estas páginas proceden del Trabajo de Investigación para la obtención del DEA, que fue dirigido por la Dra. Margarita Almela Boix, Profesora Titular de Literatura Española de la UNED.

1 José Domínguez Caparrós así lo advierte en su artículo «La novela histórica: rasgos genéricos» (La novela histórica europea, UNED, Madrid, 2000, p. 15) con estas palabras: «Al hablar de novela histórica, uno de los temas que primero se plantea es el de su definición como género. (...) Raro será el estudio sobre la novela histórica en una determinada literatura que no cuente con el planteamiento de esta cuestión». También opina lo mismo F. Unzueta en su libro La imaginación histórica y el romance nacional en Hispanoamérica, Latinoamérica Editores, Lima-Berkeley, 1996, p. 41: «La gran mayoría de los estudios tradicionales preocupados por las relaciones entre el discurso histórico y el de ficción, y aún muchos de los más recientes, giran en torno al concepto de la novela histórica».
} 
que se entiende por «Historia» puede ser objeto de cambio, de revisión conceptual. También lo es el concepto de novela histórica, pues para reconocer este subgénero literario como tal es necesaria «no solo una manera de escribir sino también una manera de leer el texto y la Historia» (Cristina Pons, pp. 42-43).

Es decir, es un género «eminentemente contractual»o lo que es lo mismo: unas convenciones culturales elaboran un preconcepto del género de novela histórica que comparten el autor y el lector. Este preconcepto de género posibilita la identificación de una novela X como novela histórica. Por lo tanto, este subgénero se reduce a una cuestión pragmática, no ontológica, como también le ocurre a cualquier otro género literario. Algunas de estas convenciones culturales son de sobra conocidas por todos: «La novela histórica casi siempre se presenta como tal y esto lo hace: bien por aclaraciones y explicaciones previas en forma de introducción, bien por llevar en el título una referencia inequívoca a tal carácter, o por aparecer en la portada la indicación de su pertenencia a una colección de narrativa histórica» (José Domínguez Caparrós, p. 35).

Si cualquier género literario, incluido el subgénero de la novela histórica, implica una historicidad que modifica su esencia y también su forma reconocerlo como tal y de leerlo, $¿$ debemos renunciar entonces a definirlo? No. Lo que ocurre es que tendremos definiciones de novela histórica diferentes según las diversas realizaciones de novelas de este género que se han ido gestando a tenor de los cambios histórico-literarios que las alumbraron.

De tal manera esto es así que: «La novela histórica se fue transformando y en este sentido la novela histórica en cuanto a modelo clásico o ideal que definiría el género no existe. El concepto de la novela histórica es una abstracción técnica, producto de un proceso deductivo que resulta en un conjunto de rasgos comunes básicos que hacen al género histórico distinto de otros géneros. Pero es una abstracción teórica que no es permanente sino que está sujeta (y requiere) continuos reajustes según la dinámica de cambio en el género, y no tanto a partir de la multiplicación de clasificaciones según variaciones y variedades» (Cristina Pons, p. 64).

Una última definición de novela histórica de $\mathrm{M}^{\mathrm{a}}$ José Candeltey del año $1990^{2}$ nos sirve de resumen de buena parte de cuanto se ha visto hasta ahora: «Bajo la denominación de novela histórica se engloban, sin embargo, novelas que sólo tienen en común el hecho de situar su acción en épocas distantes y se acogen relatos de muy diversas tendencias y estilos (...), combinan una serie de historias imaginarias con una serie de acontecimientos históricos - bien documentados - y cumplen los requisitos básicos exigidos por los eruditos: respetar la cronología y los hechos comprobados, no extralimitarse en las interpretaciones, crear un marco histórico consistente que no sea un simple telón de fondo e imaginar, pero no inventar».

Es importante destacar en esta definición cómo se alude a la heterogeneidad de las obras concretas que se agrupan bajo la denominación de novela histórica, que muchas veces no es valorada en su justo término, sobre todo cuando se le añaden prejuicios sobre la supuesta existencia de un canon ideal de este tipo de novela, coincidente con la novela de Walter Scott, para unos, o algunas del periodo del Realismo, para otros.

${ }^{2}$ Está recogida en el Trabajo de Investigación de A. Caunedo Álvarez, La novela histórica en España durante la última década (1880-1991). Recepción crítica en El País y ABC, UNED, curso 1991-1992, pp. 14-15. 
Muchos de los que han estudiado la novela histórica postmoderna o la novela histórica de un determinado tema o de una determinada literatura, generalmente hispanoamericana $^{3}$, se han enfrentado a esta cuestión, pues el corpus de novelas históricas que analizaban no coincidían en sus características principales con las que se atribuían a las novelas de Walter Scott que, en teoría, eran paradigmáticas de este subgénero novelístico. Bien porque hubiera una consciente distorsión de la historia a través del anacronismo, las omisiones o el uso de la hipérbole. Otra veces porque se daba una superposición de distintos tiempos históricos o porque los personajes protagonistas eran figuras de primer rango y no el héroe medio que ocupaba ese lugar en las novelas del genial escocés.

En otros casos porque el material histórico sobre el que operaban los personajes de ficción y los históricos pasaba de un telón de fondo a un primer plano. O bien porque la distancia temporal que Scott fijaba de al menos 70 años para tener la distancia oportuna con respecto a los hechos novelados no era respetada porque se escribía sobre hechos recientes, conocidos e incluso vividos por el autor personalmente, en algunos casos ${ }^{4}$. Todo esto llevó a estos autores a replantearse el concepto de novela histórica tal como lo fijaba la tradición literaria y también a plantearse por qué se ha venido perpetuando hasta hoy día dicho concepto.

Para Cristina Pons (p. 31), «hasta el surgimiento de la novela histórica de los últimos decenios las categorías con base en las cuales se conforma la noción de novela histórica de los últimos decenios corresponden a las de novela histórica tradicional de corte romántico o realista». Y ello es debido según Cristina Pons (p. 34) a que: «La ausencia de estudios teóricos que actualicen y reconsideren el género de la novela histórica latinoamericana parece haber colaborado a que se perpetuara el concepto de novela histórica según los parámetros de la novela histórica tradicional».

Fernando Unzueta destaca el papel que ha jugado la crítica literaria en la perpetuación de este espejismo de «novela histórica» como subgrupo uniforme, concretamente menciona las inexactitudes que contenía el tratado de George Lukács La novela históri$c a$, las cuales pesan hasta la actualidad. Por ejemplo: Lukács obvió todos los rasgos más «románticos» de las novelas de Walter Scott para dar coherencia a la lectura realista y social a la que Lukács sometió a la novelística de Scott — a pesar de su indudable raigambre romántica - y la aproximó a la novela burguesa. «En esta interpretación, entonces, se establece una continuidad narrativa entre los géneros históricos con los que no lo son; la diferencia residiría únicamente en el plano referencial» (Fernando Unzueta, p. 45). Continuidad narrativa falaz que ha dado como resultado la canonización del subgénero de novela histórica en estas dos épocas: el Romanticismo y el Realismo.

También «acusa» a Lukács de estudiar «otras versiones de la novela histórica, pero todas palidecen en comparación a la ejemplaridad de Scott, a quien presenta como precursor de la novela realista, además de considerarlo el creador y máximo responsable de

\footnotetext{
${ }^{3}$ Cristina Pons, Karl Kohut, Noé Jitrik, Alfredo Márquez Rodríguez, Fernando Unzueta, Celia Fernández Prieto, Seymour Menton.

${ }^{4}$ Como se puede observar no son simples detalles lo que separa un tipo de novela de la otra. Son aspectos muy importantes que hacen relación al tratamiento del material histórico incorporado a la novela, el cual «desempeña un papel estructural dentro de la economía de la novela histórica, y no un papel meramente ornamental o instrumental» (Crisitina Pons, p. 58). Lo que se traduce en importantes innovaciones estructurales que dan como resultado novelas históricas muy alejadas del modelo de Walter Scott.
} 
la novela histórica «verdadera» y «clásica» (Fernando Unzueta, p. 37). Cuando es bien sabido que «existen otras alternativas al modelo de Lukács en el estudio de lo histórico en la novela de la época. Estas opciones completarían los aportes que proporcionan los trabajos sobre la novela histórica» (Fernando Unzueta, p. 45). Este autor se refiere al romance nacional hispanoamericano, pero también podríamos incluir aquí el episodio nacional.

En la base de todo está según Fernando Unzueta (p. 44): «la imposibilidad de definir un género novelesco válido para distintas épocas, la dificultad de definir genéricamente la novela histórica (que lleva a universalizar los modelos específicos o se limita hacer una lista de características genéricas) y la estrecha relación de la novela histórica con las filosofías de la historia de la misma época».

\section{Clasificaciones de la NOVEla históRica}

Como hemos visto en el apartado anterior no existe una única definición de novela histórica que pueda agrupar todas las producciones novelísticas que incluyen un material histórico como elemento estructural de las mismas. Esto tiene su lógica si tenemos en cuenta que estamos hablando de un subgénero novelístico surgido hacia 1823 (fecha de la publicación de Ivanhoe, de Walter Scott, novela histórica paradigmática de este subgénero) y que llega hasta nuestros días con un inusitado vigor. Algo menos de dos siglos de producción novelística de enorme volumen - con el tema de la guerra civil española, tratado tanto de forma directa como de forma indirecta, Maryse Bertrand de $\mathrm{Mu}$ ñoz ha contabilizado 1300 títulos hasta 1990, por poner un ejemplo - que se ha visto afectada por las transformaciones que ha sufrido la novela en general con el paso del tiempo.

En casi todos los estudios de novela histórica encontramos muchas y variadas clasificaciones que responden a muchos y también variados criterios en torno a los cuales éstas se construyen. Los obstáculos a los que se tienen que enfrentar aquellos que realizan clasificaciones de novela histórica son similares a los de aquellos que clasifican la novela en general, por ejemplo:

- La falta de unanimidad a la hora de definir el término «novela», al igual que ocurre en el caso del término «novela histórica».

- La cantidad y la variedad de obras que se agrupan tanto bajo ese rótulo de «novela», como bajo el rótulo de «novela histórica».

- La escasez de estudios específicos sobre clasificación de novela, en general, y de novela histórica, en particular.

Los criterios, que aparecen en los relativamente pocos tratados de novela histórica que existen se pueden englobar en los siguientes grupos:

1. Criterio genérico:

1.1. Episodio nacional o novela histórica nacional.

1.2. La nueva novela histórica postmoderna. 
2. Criterio cronológico.

2.1. La clasificación de la novela histórica romántica española de Juan Ignacio Ferreras.

2.2. La clasificación de toda la novela histórica de Celia Fernández Prieto.

3. Criterios relacionados con el contenido.

3.1. Criterio histórico-temático. (Las clasificaciones de la novela histórica de la Antigüedad).

3.2. Criterios que se centran en la concepción de la Historia y su correlativo tratamiento del material histórico.

3.3. Criterio basado en la ideología o intencionalidad del autor.

4. Criterios formales-estructurales.

- Criterios lingüísticos-enunciativos: la persona narrativa.

- Criterio basado en el orden o la secuencia temporal.

- Criterio lingüístico puro: lenguaje arcaizante o no.

5. Criterio pragmático: el lector.

Para el presente artículo dedicado al género literario, vamos a desarrollar el primero de los criterios por estar basado en éste.

\section{Criterio genérico}

Ya se dijo que la distinción temática era la que singularizaba o identificaba a la novela histórica como subgénero novelesco de un género literario más amplio: la novela ${ }^{5}$. Pero ¿podemos dividir en otros subtipos el subgénero de novela histórica? La crítica parece casi unánime a la hora de reconocer al menos dos: el episodio nacional (también llamado novela histórica nacional) y la nueva novela histórica postmoderna. Ambos subtipos poseen características propias tanto temáticas como estructurales y formales que aconsejan situar a cada subtipo dentro de un grupo a parte.

\subsubsection{El episodio nacional o la novela histórica nacional}

Frente a algunos críticos que no consideran el episodio nacional como un subtipo de novela histórica (Casalduero y Amado Alonso) están muchos otros que sí defienden tal distinción (G. Gómez de la Serna, H. Hinterhaüser, M. de Gorgoza Fletcher, G. Ribbans, JI. Ferreras, C. Fernández Prieto, J. Huerta Calvo, A. Rodríguez Márquez, etc.). El episodio nacional se distingue de la novela histórica, de una parte, por una característica que lo emparenta con la novela histórica que narra sucesos históricos cercanos al autor: la de narrar sobre un pasado reciente, contemporáneo. Esta característica temática comporta

${ }^{5}$ Ferreras en su libro Benito Pérez Galdós y la invención de la novela histórica nacional dice a este propósito: «No hay duda de que dentro de la novela, apareció la novela histórica y que dentro de la novela histórica apareció el episodio nacional» (p. 270). Seguimos a este autor para casi todo lo dicho, pues el libro mencionado (especialmente el capítulo IV y VII) es bastante esclarecedor sobre esta cuestión. 
grandes repercusiones formales, como ya veremos. Y por otra parte, el episodio nacional se distingue por otras características intrínsecas exclusivas de este subtipo literario como la visión nacional que presenta (o en palabras de Ferreras, su universo novelesco abarcaría a toda una nación) así como una percepción de la Historia como evolución social.

La cercanía del autor con respecto al hecho histórico narrado en su novela es la primera de esas características que definen al episodio nacional. Lo narrado debe estar en la órbita de lo histórico-contemporáneo del autor.

Establecer esa limitación temporal - que expresado de ese modo queda muy impreciso - es difícil ${ }^{6}$, pero en opinión de Juan Ignacio Ferreras (1997): «Esta limitación significa que el autor está hablando de su tiempo, aunque el tiempo de la novela se retrotraiga en años a algunas generaciones. Quizás como ha señalado Gorgoza Fletcher hablando de los Episodios de Galdós, este tiempo que es memoria colectiva de alguna manera, no ha de pasar de los abuelos del autor, es decir, una novela histórica nacional tratará al límite un tema que sólo podría retrasarse en el tiempo dos o tres generaciones» (p. 14).

Ya tenemos la primera de las consecuencias del hecho de narrar hechos históricos cercanos en el tiempo: una mayor subjetivización del autor con respecto a lo que narra, pues se encuentra dentro del tiempo histórico que recrea, de tal manera que: «Es fácil comprender que ningún novelista que trate de temas contemporáneos, sobre todo si son políticos o históricos de una manera general, puede permanecer indiferente. Es más, se puede adelantar que la visión histórica, si es contemporánea, se transforma irremediablemente en visión política» (Juan Ignacio Ferreras: 1997, p. 12). Pero no solamente afecta a la subjetivización y a un marcado aliento político de la narración, el hecho de narrar sobre temas históricos cercanos influye también en otros aspectos de mayor importancia en el aspecto formal de este subtipo novelesco que es el episodio nacional. Celia Fernández Prieto ha detallado estas implicaciones formales (pp. 116-117):

- Falta el exotismo y el misterio que rodea a la novela histórica de tema lejano, la cual está más emparentada con el romance.

- Los resúmenes y las pausas explicativas se reducen considerablemente con respecto a las novelas de tema lejano pues el autor y el lector comparten un mismo tiempo histórico. Se narrativiza mucho más el contenido histórico, sobre todo a través de la dramatización de los personajes de ese contenido.

- El autor debe documentarse de forma mucho más rigurosa.

- Los acontecimientos de la Historia se imponen y determinan la trama ficcional.

- El protagonismo se reparte entre personajes inventados y personajes históricos de primer plano. La historia anónima y privada coexiste con la pública.

- Manifiesta una intencionalidad didáctica. Se plantean casi como un forma de «educación política».

Todas estas características han llevado a algunos críticos a afirmar algo parecido a lo que ocurría con la novela histórica: que el subtipo del episodio nacional sería un sub-

\footnotetext{
${ }^{6}$ En el caso de Galdós siempre había una media de treinta años entre la fecha del suceso histórico y su novelización.
} 
género con diferentes realizaciones que comenzaría con los Episodios nacionales de Galdós y continuarían hasta los escritores de novelas sobre la guerra civil española (Sender, Girondella, Max Aub, Cela, etc). Esta idea ya fue enunciada por Gaspar Gómez de la Serna en $1954^{7}$, autor que consideraba a Galdós el creador de este subtipo, el cual era definido como «la Historia como suceso» y en el cual eran incluidas tanto las novelas de $E l$ ruedo ibérico, de Valle-Inclán como las de tema de la guerra civil española de autores como Foxá, García Serrano o Gironella. Más recientemente también han adoptado esta idea Madeleine de Gogorza Fletcher y Celia Fernández Prieto; para esta última el episodio nacional sería: «Un microgénero (Jean Molino, $1975^{8}$ ) que forma parte de la tradición de la novela histórica, que presenta un sistema de índices formales, semánticos y pragmáticos que funciona como un referente para escritores posteriores como Unamuno y Baroja (aunque éstos lo utilicen para destruirlo), y que se continúa en la obra de autores como Max Aub y en la serie de novelas históricas sobre acontecimientos de la guerra civil española» (p. 116) ${ }^{9}$.

Todas estas características que trae aparejadas el hecho de narrar sobre el pasado reciente, como acabamos de ver, forman parte de una de las notas dominantes que definen el episodio nacional. Pero no es la única, según Juan Ignacio Ferreras (1997, p. 220) para que éste sea tal, también tiene que haber una visión totalizadora de la Historia de una nación. Para ello la novela tendrá uno o varios temas que serán de alcance nacional en importancia histórica, nunca un suceso o una peripecia históricos aislados, así como unos protagonistas «que tiendan a ser representativos, héroes colectivos, protagonistas llenos de significación». De tal manera que, como dice Juan Ignacio Ferreras: «El episodio nacional no es solo una novela histórica, sino una visión histórica, obligatoriamente nacional, sobre la historia reciente o contemporánea del autor» (1997: p. 220).

\subsubsection{La novela histórica postmoderna}

Javier Huerta Calvo decía sobre la novela histórica en su clasificación de los distintos tipos de novela ${ }^{10}$ que «en España hay que destacar el ambicioso propósito de Pérez Galdós en los Episodios nacionales, serie que debe situarse en el polo opuesto a la novela scottiana de corte romántico, cultivada en España por Larra (El doncel de Don Enrique el Doliente), Espronceda (Sancho Saldaña) y Enrique Gil y Carrasco (El señor de Bembibre)». Si el episodio nacional vemos que es catalogado como un tipo de novela antagónica a la novela histórica de Walter Scout, que inaugura el género, más aún lo es la nue-

\footnotetext{
${ }^{7}$ En su obra España en sus episodios nacionales. Ensayos sobre la versión literaria de la historia. Madrid, Ediciones del Movimiento, 1954, 1. . edición, 337 pp.

${ }^{8}$ Las palabras de Jean Molino que recoge Fernández Prieto están tomadas de su artículo «Qu'est-ce que le roman historique?», Revue d'Histoire Littéraire de la France, números 2-3, pp. 195-234.

${ }^{9}$ En un estudio mucho más actualizado, concretamente del año 2002, de J. Gargallo Torres, Literalidad, intertextualidad e interpretación en Míster Witt en el Cantón de Ramón J. Sender, UNED también se defiende esta idea de una continuidad de la novela histórica de tema reciente que arrancaría desde Galdós hasta la Edad de Plata de nuestra literatura.

${ }^{10}$ En Los géneros literarios: sistema e historia, Cátedra, 1999, p. 190.
} 
va novela histórica postmoderna ${ }^{11}$. Ya vimos en el apartado primero que este tipo de novela había sido el desencadenante de la polémica en torno a la definición del término «novela histórica», pues las novelas reunidas bajo esta etiqueta se diferenciaban muy y mucho del modelo clásico creado por Walter Scott.

Los ejemplos más acabados de novela histórica tal como se entiende a finales del siglo XX, y por tanto, los más alejados de novela histórica romántica pertenecen, en los albores de este nuevo tipo de novelar la historia, al ámbito literario hispanoamericano. La fecha fetiche que se suele poner como emblemática del auge de este tipo de novela es la de 1979 - según Seymour Menton (p. 31) - pues es el año de publicación de la novela de Alejo Carpentier, El arpa y la sombra, obra paradigmática de este nuevo novelar.

Pero también hay otros aspectos a tener en cuenta para considerar esa fecha como emblemática: el número de novelas publicado desde esa fecha hasta el año 1992 «excede al número de novelas histórica publicadas en los 29 años anteriores» (Seymour Menton, p. 46). Este autor ha contabilizado 193 títulos a partir de 1979 frente a los 156 títulos editados entre 1949 y 1978 . No solo es un argumento de cantidad sino también de calidad, pues: «entre los autores que la cultivan figuran algunos de los nombres más respetados de cuatro generaciones literarias que provienen de casi todos los países latinoamericanos: la primera, el cubano Alejo Carpentier (1904-1980); la segunda, el mexicano Carlos Fuentes (1929), el peruano Vargas Llosa (1936) y el brasileño Silviano Santiago (1936); la tercera del nicaragüense Sergio Ramírez (1942), el cubano Reinaldo Arenas (1943-1990) el portorriqueño Edgardo Rodríguez Juliá (1946), el mexicano Herminio Martínez (1949) y el guatemalteco Arturo Arias (1950), y la cuarta, el argentino Martín Caparrós (1957)» (Seymour Menton, p. 47).

Las características definitorias de este tipo de novela histórica se pueden resumir según Seymour Menton en seis rasgos (pp. 42-44):

1. La recreación histórica de un determinado periodo está subordinado a tres ideas de Borges: a. La imposibilidad de establecer la verdadera naturaleza de la realidad o la historia; b. La naturaleza cíclica de la historia; c. Su impredecibilidad.

2. La consciente distorsión de la historia a través del anacronismo, las omisiones o hipérboles.

3. La utilización como protagonistas de figuras históricas de primer rango.

4. La presencia de la metaficción.

5. La importancia de las referencias intertextuales.

6. La manifestación de aspectos relacionados con lo dialógico, lo carnavalesco y la heteroglosia.

Otro estudioso de este tipo de novelas, Fernando Ainsa ${ }^{12}$, advierte del peligro de generalizar demasiado al intentar buscar un único modelo cuando se trata de una produc-

11 La etiqueta «postmoderna» debe ser entendida según Karl Kohut define el sustantivo del que procede «posmodernidad» la cual sería: «en las artes una categoría metahistórica, y al mismo tiempo, una categoría histórica que definiría el presente fin de siglo». (p. 16).

${ }^{12}$ Lo citamos a través de las palabras de María Caballero en Novela histórica y posmodernidad en Manuel Mújica Láinez, Universidad de Sevilla, Secretariado de Publicaciones, 2000, pp. 21-22. La cita original está en: La novela histórica. Cuadernos de Cuadernos 1, México, UNAM, 1991. 
ción novelística que aglutina a tantos escritores de países muy diferentes en busca de sus propias señas de identidad. Para él son diez los rasgos que definen este tipo de novela histórica:

1. «Relectura de la historia desde una visión crítica del pasado y el deseo de ir a la semilla de la nacionalidad.

2. Ataque a la legitimidad y la versión oficial.

3. Multiplicidad de perspectivas, lo que implica la inexistencia de «una verdad».

4. Abolición de la distancia épica - Bakthin - y la alteridad del acontecimiento - Ricoeur-.

5. La nueva novela se acerca al acontecimiento real, pero toma distancia en relación a la historiografía oficial.

6. En ella se da la superposición de distintos tiempos históricos.

7. Documentación disimulada y pura invención conviven en el texto.

8. Las modalidades expresivas son múltiples: la metaficción se instala en las «falsas» crónicas. Se puede glosar el texto auténtico o fluctuar entre la hipérbole o lo grotesco.

9. La parodia, como fruto de una relectura distanciada por parte del narrador, suele ser una constante.

10. El humor y la mayor preocupación por el lenguaje son la muestra de que el boom pasó por la literatura hispanoamericana».

Vemos que esta clase de novela histórica incluye elementos que no aparecían en la «novela histórica clásica» como la hipérbole, lo grotesco o la pura invención en lo relativo al tratamiento del material histórico, lo cual se traduce en un alejamiento con respeto a la historiografía oficial y en un menoscabo de la fidelidad histórica.

No es de extrañar, por tanto, que críticos como Karl Kohut afirmen que «de manera general y desde ya se puede sostener que la novela histórica actual es la segunda en importancia desde la aparición de la novela histórica del romanticismo» (p. 20) no solo por la cantidad y calidad de muchas de estas novelas, sino también por sus innovaciones en cuanto al género. No obstante, y parafraseando a Kart Kohut, sería todavía más exacto afirmar que la novela histórica postmoderna es la tercera en importancia, para dejar al episodio nacional el segundo lugar dentro de esta clasificación de la novela histórica, pues fue cronológicamente anterior a aquella e igualmente innovador con respecto a ese mismo modelo establecido tiempo atrás que llamamos novela histórica romántica.

\section{BIBLIOGRAFÍA}

Alonso, A., Ensayo sobre la novela histórica. El modernismo en La Gloria de Don Ramiro, Madrid, Gredos, 1984.

CABAllero, M., Novela histórica y posmodernidad en Manuel Mújica Láinez, Universidad de Sevilla, Secretariado de Publicaciones, 2000.

DOMÍNGUEZ CAPARRÓs, J., «La novela histórica: rasgos genéricos». En: La novela histórica europea, UNED, Madrid, 2000. 
De Gogorza Fletcher, M., The Spanish Historical Novel 1870-1970, Tamesis Books Limited, Londres, 1974.

FERNÁNDEZ PRIETO, C., Historia y novela: poética de la novela histórica, Eunsa, Pamplona, 1998.

FERRERAS, J. I., El triunfo del liberalismo y la novela histórica (1800-1820), Taurus, Madrid, 1973.

FERRERAS, J. I., Benito Pérez Galdós y la invención de la novela histórica nacional, Endimión, Madrid, 1997, pp. 71-83.

García Gual, C., Apología de la novela histórica, Península, Barcelona, 2002.

- La antigüedad novelada, Anagrama, Barcelona, 1995.

GÓMEZ DE LA SERNA, G., España en sus episodios nacionales (ensayos sobre la versión literaria de la historia), Madrid, Ediciones del Movimiento, 1954.

KoHUT, K., La invención del pasado. La novela histórica en el marco de la postmodernidad, Frankfurt am Main:Vervuert, 1997.

LUKÁcs, G., La novela histórica, Grijalbo, Barcelona, 1976.

Menton, S., La nueva novela histórica de la América Latina 1979-1992, Fondo de Cultura Económico, Madrid, 1993.

NaVArRo Salazar, M. ${ }^{\mathrm{a}}$ T. (ed.), La novela histórica europea, UNED, Madrid, 2000.

- Castro García, M. ${ }^{a}$ I., «El cuestionamiento en la novela histórica contemporánea. Ejemplos en la narrativa española», pp. 93-104.

- Domínguez CAPARrós, J., «La novela histórica: rasgos genéricos», pp. 15-35.

Pons, Ma C., Memorias del olvido. La novela histórica de finales del siglo XX, Siglo Veintiuno Editores, México, 1996.

Spang, K., Géneros literarios, Síntesis, Madrid, 1996.

Spang, K., Arellano, I. y Mata, C., La novela histórica. Teoría y comentarios, Eunsa, Pamplona, 1995.

UNZUETA, F., La imaginación histórica y el romance nacional en Hispanoamérica, Latinoamérica Editores, Lima-Berkeley, 1996.

\section{TESIS DOCTORALES}

CAunedo Álvarez, A., La novela histórica en España durante la última década (1980-1991). Recepción crítica en El País y ABC, UNED, curso 1991-1992, pp. 5-72.

Gargallo Torres, J., Literalidad, intertextualidad e interpretación en Míster Witt en el Cantón de Ramón J. Sender, UNED, 2002, pp. 81-93 y pp. 160-213. 